\title{
Construction and verification of an environment and energy prediction model for Controlled Environment Housing
}

\author{
Li Yang ${ }^{1}$, Longhuan $\mathrm{Du}^{2 *}$, Chaowu Yang ${ }^{1,3}$, Chenming $\mathrm{Hu}^{1}$, Chunlin $\mathrm{Yu}^{1,3}$, Huarui $\mathrm{Du}^{1}$ and Qingyun $\mathrm{Li}^{1}$ \\ ${ }^{1}$ Animal Breeding and Genetics Key Laboratory of Sichuan Province, Sichuan Animal Science Academy, Chengdu, China \\ ${ }^{2}$ College of Architecture and Environment, Sichuan University, Chengdu, China \\ ${ }^{3}$ Sichuan Animal Science Academy, Chengdu, China
}

\begin{abstract}
In order to satisfy the healthy growth and performance of livestock and poultry, a large amount of energy is often consumed in the production process of modern livestock and poultry breeding, which is used for automatic feeding management and regulation of breeding environment. In this study, based on the ISO 13790 5R1C equivalent resistance capacitance network computing model, using the henhouse heat balance, water balance, balance of gas (ammonia, carbon dioxide concentration) principle, we developed a simple closed loop control henhouse environment and energy consumption prediction model, Through on-site validation tests, the results show that the model is reliable, and it can assist the farmer for breeding planning, house-design process and increase environmental control and energy management efficiency.
\end{abstract}

\section{Introduction}

The breeding environment in the house has an important influence on the health, growth and performance of the animals. Modern environmental control in the corral, generally adopts enclosed corral building structure, through the intelligent mechanical equipment to manipulate space for aquaculture environment, inner environment factors including temperature, humidity, air velocity and so on according to the breeding varieties and breeding stages to achieve the effective control, meet the best demand of animal growth contributed to the overall production performance to improve livestock and poultry, has increased the economic income of farmers. On the other hand, in order to achieve this goal, the environmental control system of the livestock and poultry house will heat and cool the house and remove pollutants in the house according to the season and the different stages of the animal's breeding. The process of farming often consumes a lot of energy for environmental control. The energy consumption of livestock and poultry houses, especially poultry houses, whether broilers or laying hens, is mainly used for the control of the microclimate environment in the house, according to Costantino et al. In the study of large-scale livestock and poultry farms in Europe, et al. found that electric energy consumed by environmental regulation accounted for $75.5 \%$ of all electric energy consumed by broiler raising. Accounting for $58.9 \%$ of the energy consumption of laying hens; Accounting for $27.4 \%$ of the total energy consumption of dairy cow feeding; It accounts for $50.2 \%$ of the electricity consumption of pig breeding [1]. It can be predicted that with the development of intelligent breeding equipment including environmental control equipment, the energy consumption of large-scale breeding will probably increase further. Therefore, a comprehensive understanding of the energy consumption of livestock and poultry breeding houses and the establishment of prediction models have important reference value for the design and use process of breeding farms in the future. Based on this, this study introduces a method to build energy consumption prediction model based on ISO13790, To estimate the energy consumption of climate control for Controlled Environment Housing.

\section{Model}

\subsection{Model parameters}

According to the production needs, this energy consumption model simulates the dynamic balance of heat inside and outside the house with the step length of one hour. The heat source in the house includes the production of livestock and poultry, heating of the heater, heat conduction inside and outside the house and heat generated by other machines. The cooling in the house is generally achieved by ventilation (wet curtain cooling). In different stages of breeding, the heat production of livestock and poultry has a certain proportional relationship with the body weight, and the corresponding optimal growth environment temperature is also different. Therefore, the model usually takes the daily body weight and calorie loss of chickens as input data. Other basic

\footnotetext{
*Corresponding author: longhuan_du@163.com
} 
parameters include hourly atmospheric environment parameters and solar radiation intensity.

\subsection{Model calculation process}

Figure1 shows the schematic diagram of relevant calculation. Based on the difference of the atmosphere environment outside the building and the environment inside the building with a step length of one hour, the model determines the switching state of relevant equipment, including ventilation fan, heating, lighting, wet curtain, waste cleaning, feeding, etc., and finally automatically predicts the energy consumption of environmental regulation.

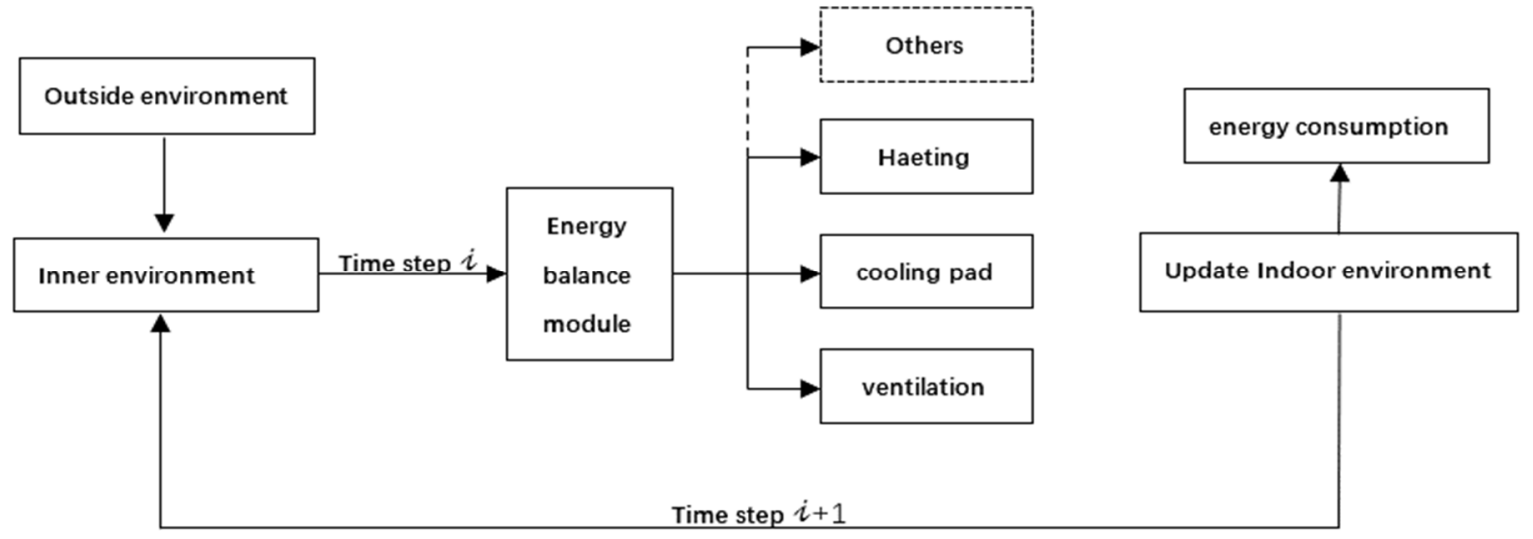

Fig.1. Schematic diagram of calculation process

\subsection{Energy balance module}

ISO13790 provides a dynamic heat balance calculation model. The working principle of the model is based on the similarity between the thermal behavior of the analyzed building and the resistor-capacitance (R-C) model (as shown in the Fig.2.). In the figure, $\varphi_{\mathrm{H} / \mathrm{C} \text {,load }}$ is the heat making or cooling capacity required in each step length. $\theta_{\text {air }}$ is the temperature in the house; $\theta_{\text {supply }}$ is the temperature of the air entering the house, When the wet curtain is not used, it is equal to the outdoor air temperature; $\theta_{\mathrm{e}}$ and $\theta_{\mathrm{s}}$ is the inner surface temperature, $\theta_{\mathrm{m}}$ is the capacitor particle temperature of the livestock house model, $\mathrm{H}_{\mathrm{ve}}$ is the ventilation heat transfer coefficient, $\mathrm{H}_{\mathrm{ve}}$ is the heat transfer coefficient of Sheene glass element; $\mathrm{H}_{\mathrm{tr}, \mathrm{w}}$ is the heat transfer coefficient of the opaque object in the house;In order to more accurately calculate the thermal mass of the livestock and poultry house, $\mathrm{H}_{\text {tr,op }}$ is further subdivided into the heat conduction of opaque objects inside and outside the house, $\mathrm{H}_{\text {trem }}$ and the calculation based on the area of the house and the surface heat transfer coefficient $\mathrm{H}_{\mathrm{is}} ; \mathrm{C}_{\mathrm{m}}$ is the heat capacity of livestock and poultry house; $\varphi_{\text {int }}$ is the internal heat production of livestock and poultry house; $\varphi_{\text {sol }}$ is the heat of the sun's rays.

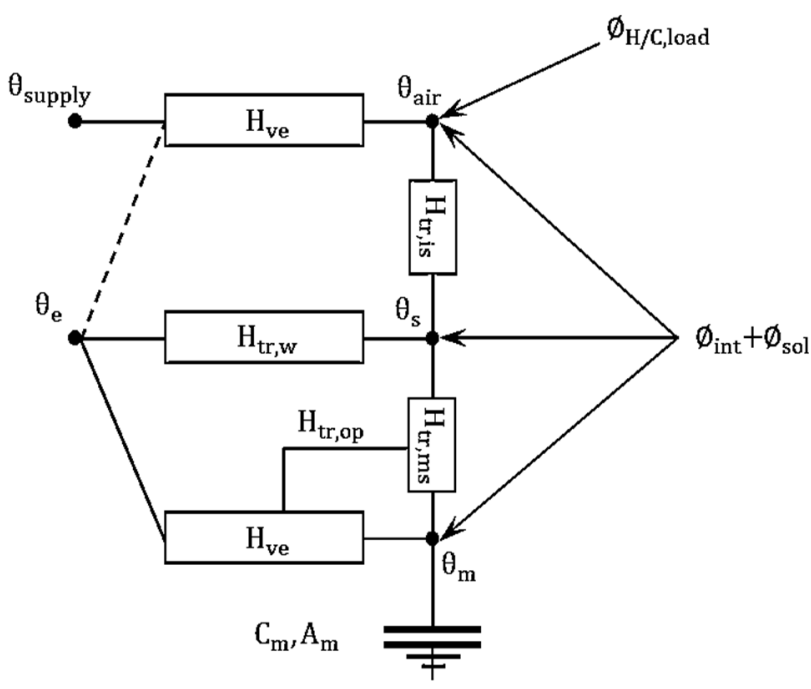

Fig.2. Five Resistance and One Capacitance (5R1C) Model

Based on the necessary exposition input to this model, the house temperature of each step length can be calculated according to the following steps:

$$
\theta_{\tau}=\frac{\theta_{\tau-1} \cdot\left[\frac{\mathrm{C}_{\mathrm{m}}}{3600}-0.5 \cdot\left(\mathrm{H}_{\mathrm{tr}, 3}+\mathrm{H}_{\mathrm{tr}, \mathrm{em}}\right)\right]+\varphi_{\mathrm{m}, \mathrm{tot}}}{\frac{\mathrm{C}_{\mathrm{m}}}{3600}+0.5 \cdot\left(\mathrm{H}_{\mathrm{tr}, 3}+\mathrm{H}_{\mathrm{tr}, \mathrm{em}}\right)}
$$

Where, $\varphi_{\mathrm{m} \text {,tot }}$ is the total heat production within the step size.

$$
\begin{gathered}
\theta_{\mathrm{m}}=\frac{\theta_{\mathrm{m}, \mathrm{\tau}}+\theta_{\mathrm{m}, \mathrm{\tau}-1}}{2} \\
\theta_{\mathrm{s}}=\frac{\mathrm{H}_{\mathrm{tr}, \mathrm{ms}} \cdot \theta_{\mathrm{m}}+\varphi_{\mathrm{st}}+\mathrm{H}_{\mathrm{tr}, \mathrm{fen}} \cdot \theta_{\mathrm{e}}+\mathrm{H}_{\mathrm{tr}, 1} \cdot\left(\theta_{\mathrm{sup}}+\frac{\varphi_{\mathrm{ia}}+\varphi_{\frac{\mathrm{H}}{\mathrm{C}} \text { load }}}{\mathrm{H}_{\mathrm{ve}}}\right)}{\mathrm{H}_{\mathrm{tr}, \mathrm{ms}}+\mathrm{H}_{\mathrm{tr}, \mathrm{fen}}+\mathrm{H}_{\mathrm{tr}, 1}} \\
\theta_{\mathrm{air}}=\frac{\mathrm{H}_{\mathrm{tr}, \mathrm{is}} \cdot \theta_{\mathrm{s}}+\mathrm{H}_{\mathrm{ve}} \cdot \theta_{\mathrm{sup}}+\varphi_{\mathrm{ia}}+\varphi_{\mathrm{H} / \mathrm{C}, \text { load }}}{\mathrm{H}_{\mathrm{tr}, \mathrm{is}}+\mathrm{H}_{\mathrm{ve}}}
\end{gathered}
$$


At this point, the air temperature $\theta_{\text {air }}$ in the livestock house at the end of the step length can be predicted.

\section{Model validation}

The model verification test was carried out in a closed hen house. The temperature sensor was used to measure and record the dynamic changes of the house temperature at 14 points in different areas in front, middle and back of the hen house over a period of time, and the average value was compared with the predicted value of the model. The test started in October 12th 2020 and lasted for 90 days. Both environmental and energy data was recorded and the considered period is believed to be adequate for the model validation since all equipment for the climate control (including all fans, radiators and evaporative pads) were used and different outdoor conditions were registered.

\section{Results and discussion}

By comparing the actual measured data of the environment controlled chicken house with the predicted results of the model (Fig.3.), the maximum error between the predicted absolute value and the measured value is only $6.85 \%$, which indicates that the model can accurately predict the dynamic trend of indoor temperature and proves that the model has a certain reliability. During the test, the actual electric energy consumption of the main environmental control equipment in the chicken house was tracked and recorded using an electric energy meter, and compared with the predicted value of the model (Table 1).The results show that the errors between the measured values of air energy heaters, ventilation fans, frequency conversion fans and other environmental control equipment and the predicted values of the model are only $4.42 \%, 5.72 \%, 11.12 \%$ and $0.89 \%$, respectively, and the total power consumption error is only $3.29 \%$, which fully proves the reliability of the model.

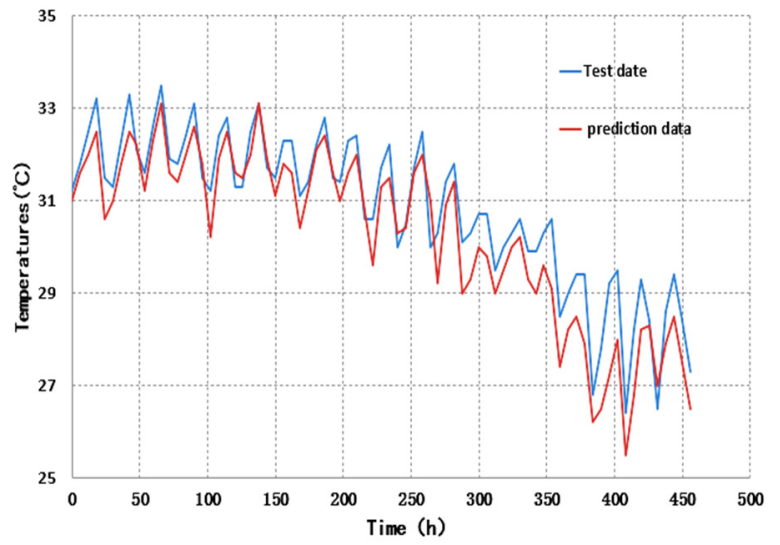

Fig.3. The actual measured values of the indoor temperature and the predicted values from the model.
Table 1. Actual electricity consumption of test value and simulated value

\begin{tabular}{|c|c|c|c|}
\hline Equipment & $\begin{array}{c}\text { Test } \\
\text { data,kWh }\end{array}$ & $\begin{array}{c}\text { Simulated } \\
\text { data,kWh }\end{array}$ & $\begin{array}{c}\text { Eror value } \\
\text { kwh }(\%)\end{array}$ \\
\hline $\begin{array}{c}\text { Air-source } \\
\text { Heat Pump } \\
\text { Water } \\
\text { Heater }\end{array}$ & 5731.38 & 5478.21 & $\begin{array}{c}-253.17 \\
(4.42 \%)\end{array}$ \\
\hline $\begin{array}{c}\text { Fixed } \\
\text { frequency } \\
\text { fan }\end{array}$ & 477.51 & 504.84 & $\begin{array}{c}27.33 \\
(5.72 \%)\end{array}$ \\
\hline $\begin{array}{c}\text { Frequency } \\
\text { conversion } \\
\text { fan }\end{array}$ & 103.58 & 115.1 & $\begin{array}{c}11.52 \\
(11.12 \%)\end{array}$ \\
\hline else & 281.62 & 279.1 & $-2.52(0.89 \%)$ \\
\hline total & 6594.09 & 6377.25 & $\begin{array}{c}-216.84 \\
(3.29 \%)\end{array}$ \\
\hline
\end{tabular}

The research on energy consumption of livestock and poultry houses is mostly carried out by using simulation software of building energy consumption, such as DOE-2, Energ plu, TNSYS, DeST, etc.[2-5], but these software are all developed for civil, commercial and public buildings, and no specific modules and functions are developed for agricultural buildings. Although livestock and poultry houses follow the same heat and mass transfer principle as civil and public buildings, the heat generation and ventilation model of active materials should be properly handled. Therefore, researchers found that these software had limitations in some aspects in the process of use, and turned to build by themselves. The capacitive resistance model of ISO13790 is one of them.

\section{Conclusions}

This study build a prediction model according to iso 13790 which is suitable for predicting the environment and energy of an controlled environment housing. based on the model validation test, results show that the model can predict the temperature change of the closed henhouse reliable trend as well as the energy consumption of the environmental control equipment. The model can be used to improve the efficiency of energy consumption of farm, optimization of process management and site selection for different climate area farms to provide important reference information and technical support.

\section{Acknowledgement}

This work was supported by Chinese National Agric ulture Research System (CARS-41-G04), Key Techno logy Support Program of Sichuan Province (2019YF N0009, 2021YFYZ0031, 21ZDYF2278), Sichuan Pro vincial Finance Operation Special Project (SASA2020 CZYX002, SASA2020CZYX007) and Sichuan Provin cial Finance Operation Special Project(2020YFN0065). 


\section{References}

1. Costantino A, Fabrizio E, Biglia A, , et al. J. Energy Procedia, 101,(2016)

2. Yang W,Baoming Li,Chao Liang,Weichao Zheng.J.Computers and Electronics in Agriculture, 168,(2020)

3. Enrico Fabrizio,Andrea Ghiggini,Mauro Bariani. doi:10.13031/aim.201701480.(2017)

4. Ahachad M, Belarbi R, Bouaziz N, et al. J. Em J Food Agri, 20(1),(2008)

5. Axaopoulos P, Panagakis P, Axaopoulos I. J. Energy and Buildings, 84:403-411,(2014) 